\title{
Predictors of Superstitious Beliefs
}

Patrick Kwaku Ofori, David Tod, and David Lavallee (2017) Predictors of superstitious beliefs, Journal Of Psychology In Africa Vol. 27 , Iss. 1,2017.

http://www.tandfonline.com/doi/abs/10.1080/14330237.2016.1185909 


\title{
Predictors of Superstitious Beliefs
}

\begin{abstract}
This study investigated whether relationships exist among, personal control, coping mechanism, primary control, secondary control and superstitious beliefs. The participants were 375 Ghanaian student athletes (females $=44 \%$ ). They completed measures of self-reported superstitious beliefs, personal control, coping mechanisms, primary and secondary control strategies. The data were analyzed to evaluate the correlates of both positive and negative superstitious beliefs and how constructs of personal control, coping mechanisms and control strategies, predict positive and negative superstitious beliefs. The results indicated that personal control, coping mechanisms and control strategies were predictors of negative and positive superstitious beliefs. In the final model Exaggerated internal control, God-mediated control, emotional support, and substance use were predictors of negative superstitions. Exaggerated internal control, Substance use, Emotional support and Acceptance were predictors of positive superstitions. Athletes may activate different types of superstitious beliefs to cope and gain control in situations of uncertainty.
\end{abstract}

Key Words: Ghana, coping mechanism, personal control, primary control, secondary control, and positive and negative superstitious beliefs. 


\section{Predictors of Superstitious Beliefs}

Superstition has persisted throughout human history, and has been present in virtually every human society throughout history (Vyse, 1997). It permeates the entire sporting world. Sport is one permeated by collective adherence to a number of various superstitions and rituals (e.g., Lawrence, 2005; Miller, 2008). Individual athletes also are known to practice certain superstitious or ritualistic behaviours of their own, apart from a collective body, such as their team. As an example, Michael Jordan wore blue University of North Carolina shorts under his Bull's uniform for good luck while Tiger Woods always wears red on Sundays as his mother believes it is a lucky colour for him (Wargo, 2008). The broader aim of this study is to ascertain the psychological functions of these beliefs and if they impact on the athletes coping and control strategies. The study intents to establish if positive and negatives serve the similar or different psychological functions.

\section{Ritualistic behaviour in Sporting}

Several researchers have analyzed sports practice as ritual performance (Archetti, 1999; Birrell, 1981), sport fans behaviour as ritualistic (Cottingham, 2012) and ritual behaviour by athletes and teams (Broch, 2013; Gmelch, 2004). Ritual performances by athletes are thoroughly documented. For instance, soccer players engaged in team rituals, lucky numbers, lucky charms and clothing rituals (Ofori, Biddle and Lavallee, 2012), wrestlers always walking with the left foot first onto the mat (Kristiansen, Roberts and Abrahamsen, 2008), Catholic athletes painting an imaginary cross before every game (Gmelch, 2004). There is emerging evidence to suggest

that some athletes use superstitious practices as both a coping mechanism to deal with stress and anxiety and to facilitate performance enhancement in sport (Park, 2000). Superstitious practices also provide a means for athletes to gain confidence and feelings of control in competitive 


\section{Predictors of Superstitious Beliefs}

situations (Becker, 1975). Thus, superstitious behaviors function as a sort of "psychological placebo" (Neil, 1980), reducing anxiety, building confidence, and helping athletes to enhance their performance. For example, professional footballers who played at the top level engaged in superstitious rituals to cope with competitive stress (Ofori, et al, 2012).

Past research has differentiated between superstitious behaviors and pre-performance routines (Cohn, 1990). Pre-performance routines (PR) are learned, behavioural, and cognitive strategies intentionally used by athletes to facilitate physical performance (Cohn, 1990). Generally speaking, a major difference between superstitions and PR are that athletes control the PR, while athletes often feel controlled by superstitions. Superstitious behaviours differ from a preperformance normal routine in that the person gives the action a special, magical significance. Superstitious behaviours and rituals are different from pre-performance routines (PR) by their means of acquisition, and its measureable impact it has on performance. More so, superstition often offers no logical progression to facilitate skill performance. PR usually has a specific benefit, or provides a warm-up (psychological and/or physical) routine, for the performance of a skill. Superstitious rituals are encouraged by the social influence of people around us. It normally grows, develops and maintains out of accidental reinforcement or social influence, combined with accidental reinforcement. For example athletes may learn their superstitions from team mates and family members (Ofori, 2013). However, the distinction between superstition and preparing for a game is not always clear. For example an athlete engaging a meditation before a game may be described as superstitious whereas to the athlete such behaviour forms part of his pre-performance routine. 


\section{Predictors of Superstitious Beliefs}

Superstitious behavior is an act that has no clear cut technical function in execution of skill, yet the actor believed it has a power to control luck and /or other external factors (Morgan, 1996). Superstitious beliefs are thoughts that are initiated by anxious individuals with strong need for

control, in an attempt to overcome perceived uncertainty in their environment (Kienan, 2002). The distinction between superstitious belief and superstitious behaviour is rather subtle, since one is sometimes defined in terms of the other. Belief, like attitude, is an intervening variable, (i.e. it cannot be directly observed but must be inferred from variables which are themselves observable). Superstitious beliefs may serve as the initiation of superstitious rituals but superstitious behavior will serve as maintenance of superstitious rituals. People act, and perceive things in accordance with their belief systems and these beliefs can influence emotional states (Jones and Swain, 1995) and attentional processes (Wiseman, 2004).

\section{Mechanisms of Action}

Superstition has an influence on performance because of the perceived increased optimism and decreased stress (Damisch et al., 2010), and perceived control (Keinan, 1994; Whitson, \& Galinsky, 2008). These are considered next:

\section{Increased optimism.}

Superstitious thinking might increase an athlete sense of optimism through self-fulfilling prophecy (Wiseman \& Watt, 2004). This is because a belief that an athletic context can be won as a consequence of some superstitious rituals, may increase the athlete confidence. Superstition can help an athlete understand what is happening in his or her athletic milieu because it offers explanations and reasons for occurrences that are otherwise baffling or unfamiliar. This makes the athlete's world more understandable, predictable, and controllable. For instance, the belief that making the sign of the cross before entering the field of play will bring good luck or improve 


\section{Predictors of Superstitious Beliefs}

the footballer's chances of scoring a goal. This can eventually enhance the athlete's selfconfidence.

Decreased stress. Superstitions fulfil a general cathartic function for those who believes in them. Superstitious beliefs invoked during instances of uncontrollability may prevent or interrupt subsequent performance impairment (Dudley 1999). Previous studies in health care have also shown beneficial physiological effects, such as pain relief (Thompson 1981; Wager, Rilling, Smith, et al. 2004) and reduction of stress (Kiecolt -Glaser, 1995). An increasing number of studies suggest that people adopt superstitious beliefs and strategies as a coping mechanism when in situations of uncertainty and stress (Case, 2004; Keinan 1994; Keinan 2002). The illusion of control and superstition, although seemingly irrational, may be an adaptive response to an uncertain world (Haselton and Nettle, 2006). Superstition helps its users to cope with anxiety, uncertainties and uncontrollable outcomes. Lazarus and Folkman (1984) examined two types of coping: active coping, which involves solving stress-related problems by removing stressors, and palliative coping, which aims to regulate or reduce the emotional stress resulting from stressors. These researchers found that when action can result in productive outcomes people tend to employ active coping strategies and when conditions are uncontrollable people rely on palliative coping strategies (see also Case, et al. 2004).

Perceived control. Perceived control is the belief that one has the ability to influence outcomes that are beyond one's reach (e.g., perceived influence over outcomes that are largely determined by chance; see Langer, 1975; Taylor \& Brown, 1988; Thompson, Armstrong, \& Thomas, 1998). Prior research has shown that illusory control is caused by the presence of cues related to having control (Langer, 1975; Thompson et al., 1998). It is well established that an absence of perceived control leads to depression, pessimism, and withdrawal from challenging situations (e.g., 


\section{Predictors of Superstitious Beliefs}

Peterson \& Seligman, 1984; Price, Choi, \& Vinokur, 2002) and the feeling of control or stability can help calm an athlete before a contest (Ofori, Tod, \& Lavallee, in press). Possessing a general sense of control leads to self-esteem, optimism, and agency (e.g., Bandura, 1989; Scheier, Carver, \& Bridges, 1994; Skinner, 1995) and allaying excitement and anxiety, while also increasing perceived confidence (Becker, 1975). Given the importance of these effects on athletes performance and well-being, it is not surprising that scholars have invested a great deal of effort in identifying the determinants of perceived control (for reviews, see Heckhausen \& Schulz, 1995; Skinner, 1995).

Perceived control can have psychological benefits, as in the case of superstitious rituals in sports (Schippers and Van Lange 2006). It is argued that the uncontrollability of conditions is a crucial factor in determining whether or not superstitions reduce anxiety. Athletes do not respond to all forms of stress with superstitious responses, presumably because some stress is elicited by conditions that appropriate action can rectify. Superstitious beliefs are anticipated to emerge under conditions in which one lacks control and instrumental responses are limited. Researchers like, Rothbaum, Weisz, and Snyder, (1982) contended that when attempts are made to change outcomes instrumentally, the process of control is primary. Primary control striving refers to an athlete's attempts to alter the external world so that it fits with their delicate needs and desires. Instances of primary control striving are evident and persistent in goal striving or the investment of time and effort, if difficulties emerge. Nonetheless, the process of control is secondary when attempts are made to achieve a feeling of control when actual control is perceived as implausible.

Athlete may attain this feeling of control by accommodating existing realities (e.g., adjusting expectations, finding meaning in events, activating superstition). Secondary control striving is 


\section{Predictors of Superstitious Beliefs}

normally targeted at the internal world and involves individuals' endeavours to influence their own motivation, emotion and mental representations (Rothbaum et al., 1982). Morling and Evered (2006) defined secondary control as people attempt to adjust some aspect of the self and accept circumstances as they are. Heckhausen, Wrosch, and Fleeson (2001) operationalized secondary control into two categories. First, selective secondary control (SSC) help athletes stay focused on chosen primary control goals. An example of operationalization of SSC from an athlete perspective will be 'Once I decide what I need to do to improve my performance, I avoid behaviors that could distract me from achieving my goals.' The second category of secondary control in their model, compensatory secondary control (CSC) help athletes regain motivation for primary control when faced with a challenge. Examples of operationalizations of CSC from an athlete perspective will be 'When something becomes too difficult, I can put it out of my thoughts' and, 'When things don't work out for me, I tell myself it was just bad luck.' These items make theoretical sense, in accordance with their view that CSC compensates for lost primary control in order to motivate further primary control. Case, Fitness, Cairns, \& Stevenson's (2004) findings divulged that superstitious beliefs act as a backup when primary control decreased.

Locus of control (LOC) is the extent to which an athlete report a sense of personal control. LOC has been dichotomized as internal or external (Rotter, 1966). Athlete with an internal LOC judges an event occurs as a product of his/her own ability, effort, or actions. An athlete with an external LOC reckons that an event is the product of chance, luck, or the influence of outside forces. In a related vein it can be said that 'Internalizers' attempt to gain control by approaching the problem or the situation head on (-instrumentation) without seeking external assistance (supernatural forces). One essential attribute of 'Externalizers' is that they have diminished or 


\section{Predictors of Superstitious Beliefs}

nonexistent primary control measures, hence they perceive reliance on superstition as a secondary control strategy (Ofori, Tod, and Lavallee, in press). Findings by Van Raalte, Brewer, Newmerof and Linder (1991) illustrated that psychology students believed the more their actions allowed them to take some control over chance events, the more likely they were to exhibit superstitious behavior in a golf putting task. Peterson (1978) found a positive relationship between an external locus of control and belief in self-oriented superstitions whereas GrothMarnat and Pegden (1998) found that an internal locus of control was related to stronger beliefs in superstitions. Tobacyk, Nagot and Miller (1988) found that greater personal efficacy control and greater interpersonal control corresponded with less belief in superstition. What is unclear from these literature reviews are the type of superstitious beliefs (positive or negative).

The present study. These beneficial functions of superstition may not be enough to explain the high prevalence of superstitious beliefs among these professional groups, or their continuous maintenance. Existing findings, however, do support the notion that the frequency and types of superstitious beliefs are found in sport differs according to the playing level and gender, but none have established additional predictors of superstitious beliefs. Even if superstitious beliefs may serve as the initiation of superstitious rituals, and superstitious behaviour may serve as maintenance of superstitious rituals for athletes searching for meaning in their inexplicable, uncertain and unpredictable sporting world, then there is the need for further investigation. We argued that athletes may differ in the type of superstitious beliefs that they engaged in, and that such differences would be informed by different motives or their orientation. This could affect whether positive and negative superstitious beliefs are activated in certain occasion and if they 


\section{Predictors of Superstitious Beliefs}

serve similar psychological functions. Hence, there is the need for a clear distinction between negative and positive superstitions beliefs and their psychological functions.

Further research on superstition and the preceding variables, is needed to supply a connecting link between certain personality and situational factors on one hand and the type of belief (positive or negative) on the other. The frequency and types of superstitious behaviours found in sport are documented in several studies (Buhrmann, Brown and Zaugg, 1982; Fischer, 1997), none has established how negative and superstitious beliefs relate to coping, control strategies and personal control. It is also unclear from this research whether negative or positive superstitions elicit different psychological functions. Could it be that positive and negative superstitious beliefs are perform different psychological benefits to athletes? Athletes engaged in superstition in terms of warding off bad luck and bringing good luck, gain control and cope with uncertainties.

Most of the studies on superstition were conducted using the superstition subscale of the Paranormal Belief Scale (Tobacyk, 2004; Tobacyk \& Milford, 1983). This instrument, however, only consists of items assessing so-called "negative" superstition, which refer to "bad luck" (e.g. breaking a mirror, the number 13, black cats), and neglects "positive" superstitions, which refer to lucky events (e.g. carrying a charm, crossing fingers, touching wood). Both negative and positive superstitions may serve different psychological functions. Negative superstitions elicit bad luck which has debilitative consequences on the athletes' performance, while positive superstitions are deemed to elicit good luck, which can improve self-efficacy. Wiseman and Watt (2004) conducted an empirical study demonstrating that these positive superstitions matter too. This study has add to the existing sport psychology in the sense that it measures superstition using a belief in superstition questionnaire scale (Wiseman and Watt, 2004) that measures 


\section{Predictors of Superstitious Beliefs}

positive and negative superstitious beliefs within a sporting milieu. There has been an exceedingly small amount of research in sports psychology that has taken these distinctions into consideration. This makes it difficult to interpret research findings on personality and environmental correlates of superstitiousness in an unambiguous manner.

However researchers have not assessed which measures of control and coping predict which type of superstition be it positive superstitions (that increase good luck or beneficial outcomes), or negative superstitions (that ward off bad luck or negative outcomes).

Goals of the study. We are interested in evaluating the correlates of both positive and negative superstitious beliefs. Accordingly, we aimed to improve on the existing literature on superstitious belief and build upon past work, particularly the work of Wiseman and Watt's (2004) by assessing the predictors of positive and negative superstitious beliefs. The study addressed the following questions:

1. What is the relationship between measures of control strategies, coping, personal control, and positive and negative superstitious beliefs?

2. Which of these measures of control strategies, coping, personal control is more likely to predict negative superstitious beliefs?

3. Which of these measures of control strategies, coping, personal control is more likely to predict positive superstitious beliefs?

Athletes rely on superstitious thoughts and practices in their daily routines gain control and cope with uncertainty (Kienan, 2002). To date, little is known about the exact control strategies, personal control and coping mechanisms that predict the potential benefits of such superstitions. 


\section{Predictors of Superstitious Beliefs}

The present study sought to address this gap by demonstrating that CSC, God-mediated control and exaggerated internal control, substance use and emotional support were significant predictors of negative superstitious beliefs.

\section{Method}

\section{Participants}

The participants were 375 Ghanaian student athletes (females $=44 \%$ ) (See Table 1 for the sample chacteristics). They have all represented their Universities at the Ghana Universities Games. They consisted of both team and individual sport athletes.

\section{Procedure}

The University Ethics Committee sanctioned the study before data collection took place in Ghana. All questionnaires for the study were piloted to screen the questions and to establish the time needed to complete the survey to enable us plan the study. The purpose of this study was explained to participants in this investigation before they were given the set of surveys. After the explanation, all participants were asked to read and sign the informed consent form.

Administered by the first author, each group of students completed the inventories during their tutorial periods. No tutors/ coaches were present during the administration of the questionnaires. The inventories were administered in the following order: demographic questionnaire, the Belief in Superstition Questionnaire (BSQ), the Measurement Instrument for Primary and Secondary Control Strategies, the Belief in Personal Control Scale and Brief COPE. 


\section{Predictors of Superstitious Beliefs}

\section{Instrumentation}

The Belief in Superstition Questionnaire (BSQ: Wiseman \& Watt, 2004) was used to measure types of superstitious beliefs (positive or negative) as the dependent variables It has two subscales, that is positive superstitious beliefs and negative superstitious beliefsParticipants were asked to indicate the degree to which they endorse three negative and three positive superstitious beliefs using a Likert scale with five response options (anchored with Definitely Yes and Definitely No). The three negative items concerned walking under a ladder (Have you avoided walking under a ladder because it is associated with bad luck?), breaking a mirror (Would you be anxious about breaking a mirror because it is thought to cause bad luck?) and the number 13 (Are you superstitious about the number 13?). The three positive items concerned crossing fingers (Do you say fingers crossed? or actually cross your fingers?), touching wood (Do you say touch wood or actually touch or knock on wood?) and carrying a lucky charm (Do you sometimes carry a lucky charm or object?). Wiseman and Watt (2004) did not report validation data to support their Superstitious beliefs scales. Specifically, they did not report data regarding internal consistency or whether their scales were related to other variables known to be closely associated with superstitious belief (e.g., locus of control [LOC]). For this study, all the six items correlated positively with each other $(\mathrm{r}=.22-.65, \mathrm{p}<.001)$. The reliability of scores from the BSQ scale was Cronbach's $\alpha=.92$.

The Measurement Instrument for Primary and Secondary Control Strategies (Peng and Lachman, 1994). Control strategies were measured with a 14-item Measurement Instrument for Primary and Secondary Control Strategies instrument using a four-point Likert scale $(1=$ not at all, $4=\mathrm{a}$ lot). The participants indicated how well the items described them. Wrosch, Heckhausen and Lachman (2000) conducted an exploratory factor analysis which confirmed the 


\section{Predictors of Superstitious Beliefs}

theoretically driven three-factor model. They labelled the three scales of control strategies as “persistence in goal striving (primary control)" (Cronbach's a = .77), "positive reappraisals (secondary control)" (Cronbach's a = .78), and "lowering aspirations (secondary control)" (Cronbach's $\mathrm{a}=.63$ ). They provided evidence for the validity of scores from the three subscales of control strategies when they performed zero-order correlations with generalised control beliefs (mastery; e.g., Lachman \& Weaver, 1998a; Pearlin \& Schooler, 1978). Both, persistence $(\mathrm{r}=.47$, $\mathrm{p}<.01)$ and positive reappraisals $(\mathrm{r}=.39, \mathrm{p}<.01)$ showed positive correlations with mastery beliefs, whereas lowering aspirations was negatively correlated with mastery beliefs $(r=-.20, p<$ $.01)$.

The Belief in Personal Control Scale (BPCS: Berrenberg, 1987) was utilised to measure personal control. The Belief in Personal Control Scale (BPCS) is a 45-item instrument used to measure three dimensions of perceptions of personal control: external control (ExtC), exaggerated control dimensions (ExagC) dimensions and God-mediated dimension (GM). ExtC assesses the extent to which an individual believes his or her outcomes are self-produced (internally) or produced by fate or others (externally). ExagC dimension measures an extreme and unrealistic belief in personal control. The God-mediated dimension measures the belief that God can be solicited in the attainment of outcomes. This dimension allows for the important distinction to be made between individuals who believe that they have little or no control over their outcomes (externals) versus those who believe they control outcomes indirectly through God. A higher score of ExtC means more perceptions of internal control, higher scores of ExagC suggest exaggerated belief in control and higher GM scores indicate less belief in God as a mediator of control. The reliability of each of the three factors was established using Cronbach's 


\section{Predictors of Superstitious Beliefs}

alpha as a measure of internal consistency. The scores from the test achieved a reliabilities of .85 (F1 - internal), .88 (F2 - exaggerated), and .97 (F3 - mediator). The BPCS has been found to have excellent construct validity with a range of .85 - .95 (Berrenberg, 1987).

The Brief COPE (Carver, 1997) was used to measure the coping strategies of participants. It comprises a total of 28 items, made up of the following subscales (each of which have 2 items) self-distraction, active coping, denial, substance use, emotional support, instrumental support, behavioral disengagement, venting, positive reframing, planning, humour, acceptance, religion and self-blame. This measure has been tested on a variety of populations (Perczek, Carver, Price, \& Pozo-Kaderman ${ }_{2}$ 2000), and the measure has been validated and shown to be reliable on several populations (Carver; Perczek et al. 2000).

\section{Data Analysis.}

Sequential multiple regression was used to asses if measures of secondary control, personal control and coping strategies would predict positive and negative superstitious beliefs. Demographic variables were controlled to establish a distinct contribution of control strategies, personal control and coping variables at step 1, step 2, step 3 and step 4, respectively, in the analysis. Ethnicity especially controlled because of the perception in Ghana that some tribesare more superstitious than others. Secondary control measures (SCC and CSC) were entered first because of the greater theoretical importance of secondary control in superstition research (Rothbaum, Weisz, and Snyder, 1982). Personal control variables (ExagC, ExtC, GM) were entered second because of its significance in the superstition literature (Fluke, Webster, \& Saucier, 2014). Coping mechanism constructs were entered at the fourth stage. Researchers have 


\section{Predictors of Superstitious Beliefs}

found a link between holding superstitions and a need to cope with life's uncontrollability (Edis, 2000; Hughes, 2002; Irwin, 1994). Regression diagnostics were computed to assess the presence of bias in the results and to assess the satisfaction of regression assumptions. There was no evidence of predictor multicollinearity because tolerance values were well above 0.2 , and variance inflation factor values were close to 1 (Field, 2013). Cook's and Mahalanobis distances were inside cut off values indicating no influential cases, and these values, along with residual plots, indicated no obvious outliers (Field, 2013). The Durbin-Watson tests were nonsignificant indicating that residuals were independent. Preliminary analyses were conducted to ensure no violation of the assumptions of normality, linearity, multicollinearity and homoscedasticity. In summary, regression diagnostics did not provide evidence of bias in the results, and they can be generalized back to the population under study.

\section{Results}

\section{Descriptive statistics.}

Table 2 presents the mean values, SDs, and correlations among the variables. Pearson correlation coefficients were obtained among measures of coping, belief in personal control, control strategies, and positive and negative superstitious beliefs (See Table 3). Significant positive correlations $(p<.05)$ emerged between positive superstitious beliefs and self-distraction (.13), substance use (.35), emotional support (.22), humour (.17), self- blame (.28), general external control (.17), God-mediated control (.43) and compensatory secondary control (CSC) (.2), while 


\section{Predictors of Superstitious Beliefs}

significant negative correlations emerged between positive superstitious beliefs and active coping (-.12), planning (-.15), acceptance (-.16), religion (-.41), exaggerated internal control ($.13)$ and selective secondary control (SSC) (-.23). Significant positive correlations were found between negative superstitious beliefs and substance use (.30), emotional support (.20), behaviour disengagement (.12), self-blame (.21), general external control (.17), God-mediated control (.34) and CSC (.21), while significant negative correlations were found between negative superstitious beliefs and positive reframing (-.11), planning (-.16), religion (-.35), exaggerated internal control and SSC (-.15).

\section{Predicting Negative Superstition from Control and Coping Strategies}

Sequential multiple regression was used to assess whether measures of secondary control, personal control and coping strategies would predict negative superstitious beliefs. Table 4 presents the results from the sequential multiple regression to predict negative superstitious beliefs from measures of secondary control, personal control and coping strategies predicting after controlling for age, gender and ethnicity. As evident from Table 4, age, gender and ethnicity were entered at Step 1, explaining $18.3 \%$ of the variance in negative superstitious beliefs. After entry of the measures of secondary control at Step 2, the total variance explained by the model as a whole was $22 \%, F(6,344)=16.28, p<.001$. The two secondary control measures explained an additional $4 \%$ of the variance in negative superstitious beliefs, after controlling for age, gender and ethnicity, $R$ squared change $=.04, F$ change $(2,344)=8.41$, $p<.001$. After entry of the measures of personal control at Step 3, the total variance explained by the model as a whole was $28 \%, F(9,341)=14.46, p<.001$. The three personal control measures explained an additional $6 \%$ of the variance in negative superstitious beliefs, after controlling for 


\section{Predictors of Superstitious Beliefs}

age, gender, ethnicity, SSC and CSC, $R$ squared change $=.06, F$ change $(3,341)=8.63, p<.001$. In Step 4, the coping mechanism measures were entered, and the total variance explained by the model as a whole was $31 \%, F(15,335)=10.15, p<.001$. The six coping mechanism measures explained an additional $4 \%$ of the variance in negative superstitious beliefs, after controlling for age, gender, ethnicity, SSC, CSC, general external control, God-mediated control and exaggerated internal control, $R$ squared change $=.04, F$ change $(6,335)=2.94, p<.05$.

In the final model, two measures of personal control were statistically significant, with exaggerated internal control recording a higher beta value (beta $=-.17, p<.05$ ) than Godmediated control (beta $=.16, p<.05$ ). Only two measures of the coping mechanisms were statistically significant, with emotional support recording a higher beta value (beta $=.13, p<.05$ ) than substance use (beta $=.12, p<.05)$.

\section{Predicting Positive Superstition from Control and Coping Strategies}

Table 5 shows the results from predicting positive superstitious beliefs from measures of secondary control, personal control and coping strategies after controlling age, gender and ethnicity. As in Table 5, age, gender and ethnicity were entered at Step 1, explaining 27.3\% of the variance in positive superstitious beliefs. After entry of the measures of secondary control at Step 2, the total variance explained by the model as a whole was $32 \%, F(6,344)=27, p<.001$. The two secondary control measures explained an additional $5 \%$ of the variance in positive superstitious beliefs, after controlling for age, gender and ethnicity, $R$ squared change $=.05, F$ change $(2,344)=12, p<.001$. After entry of the measures of personal control at Step 3, the total variance explained by the model as a whole was $36.4 \%, F(9,341)=21.67 p<.001$. The three personal control measures explained an additional $4 \%$ of the variance in positive superstitious 


\section{Predictors of Superstitious Beliefs}

beliefs, after controlling for age, gender, ethnicity, SSC and CSC, $R$ squared change $=.04, F$ change $(3,341)=7.81, p<.001$. In Step 4, the coping mechanism measures were entered, and the total variance explained by the model as a whole was $43 \%, F(17,333)=14.93, p<.001$. The eight coping mechanism measures explained an additional $7 \%$ of the variance in positive superstitious beliefs, after controlling for age, gender, ethnicity, SSC, CSC, general external control, God-mediated control and exaggerated internal control, $R$ squared change $=.07, F$ change $(8,333)=5.03, p<.001$.

In the final model, only SSC as a measure of secondary control was statistically significant. The two measures of personal control were statistically significant, with God-mediated control (beta $=.18, p<.05)$ recording a higher beta value and exaggerated internal control recording a lower beta value (beta $=-.13, p<.05)$. Only three coping mechanism measures were statistically significant, with substance use recording a higher beta value (beta $=.15, p<.05$ ) than emotional support $($ beta $=.14, p<.05)$ and acceptance $($ beta $=-.14, p<.05)$.

\section{Discussion}

One purpose of this study was to investigate the relationships between personal control, coping, control strategies and superstitious beliefs in student athletes. Selective Secondary Control (SSC), Compensatory Secondary Control (CSC), God-mediated control, exaggerated internal control, substance use, emotional support and acceptance were significant predictors of positive superstitious belief. The present study extent the findings of Todd \& Brown (2003) that two measure of personal control(GM and ExagC) and coping measure (Substance use and Emotional support) emerged as the significant predictor of superstition and Park (2000) assertions that superstitious practices served as a coping mechanism for athletes to deal with stress and anxiety. 


\section{Predictors of Superstitious Beliefs}

A significant correlation was found between exaggerated internal control and superstitious belief types. These findings are consistent with Wiseman \& Watt's (2004) findings that psychological correlates of superstitious belief vary depending on whether the belief is in positive or negative superstitions. Judging from the items that constitute positive superstition, such as "carrying a charm to bring good luck", and that of negative superstition scale such as "breaking a mirror", it can be deduced that the definition that is magically given to a belief determines its consequence as either functional or harmful to the believer. Given the examples above, it was not surprising that Wiseman \& Watt, (2004) found scores on a negative superstition sub-scale correlated with a range of measures reflecting poor psychological adjustment. Hence, the present findings suggest the need for any reliable and valid measure of superstitious belief to take into consideration both positive and negative superstitions especially in the sporting world.

Further, there was no relationship between primary control and superstitious beliefs (negative and positive). Although a significant relationship existing between superstitious beliefs and secondary control (SSC and CSC). The more an athlete uses SSC, the less he/she believes in superstitions. On the other hand, the more an athlete activates CSC, the greater their belief in superstitions. This finding is in agreement with Rothbaum et al.'s (1982) account of secondary control; participants appeared to align themselves with the forces of paranormal beliefs in an attempt to gain control. This suggests that the process of control, which is served by a belief in superstitions, is Compensatory Secondary Control CSC). So in their quest to adapt to the realities on the ground, athletes align themselves with superstitions as a means of regaining control and as a pathway from loss of primary control back to primary control. Aligning oneself with luck may help to gain control of uncertain situations (Burger \& Lynn, 2005) as well as increasing the athlete's self-efficacy (Damisch, Stoberock, \& Mussweiler, 2010). The present study is 


\section{Predictors of Superstitious Beliefs}

consistent with Wright \& Erdal (2008) claims that superstitions may be generated by needs to establish control. In situations of uncertainty, the attempt to gain control through superstitions may have a positive affect on self-efficacy and eventually performance.

In particular, the results suggest that people may enact their positive superstitious beliefs and religion (as assessed by God mediated control) as a coping mechanism and as a secondary control strategy, to give themselves the comfort of feeling in control under conditions of impending failure. Accordingly, positive superstitious beliefs might have resulted from the person enacting a positive reappraisal of the situation. It can be deduced from the present findings that people are likely to engage in positive superstitions only when skill or actual ability to control outcomes (primary control) is low, and to cope with stress of impending failure. Belief in positive superstitions could have their basis in quite different mechanisms, such as the promotion of self-efficacy and optimism, as posited by Wiseman \& Watt (2004). This might be one of the reasons why both secondary control strategies (SSC and CSC) predicted positive superstitious beliefs but not negative superstitious beliefs. Thus, the assertion that secondary control may function as a buffer against negative affect or under conditions of low primary control is only applicable when the secondary control strategies are concerned with positive superstitious beliefs.

God-mediated control and exaggerated internal control significantly predicted negative superstitious beliefs. An athlete who believes his or her outcomes are self-produced (internally) or produced by fate or others (externality), and those who believe that God can be solicited in the attainment of outcomes, are more likely to perceive a threat situation as being mitigated by a bad omen (bad luck) (Wiseman \& Watt, 2004). As noted earlier, the findings show that there are 


\section{Predictors of Superstitious Beliefs}

many ways in which people cope when their primary control strategies fail them; those who choose to adopt substance use and emotional support are most likely to attribute their failure to negative superstitious beliefs. These attributions may inform their adoption of a secondary control strategy to cope with the situation, which in some cases may include supernatural meanings. Thus, in their quest to re-establish control or understand why their instrumental abilities and skill have eluded them in such a critical period, superstitions offer an antidote for their precarious condition.

\section{Implications for Research and Practice in Sporting}

Clearly, each athlete needs to determine their own type of superstitious beliefs, but as Simons (1992) indicates, "waiting for something or someone to magically turn potential into reality is a person who will come up short" (p. 17). Therefore, sport psychologists should work with athletes in order to facilitate control strategies, coping strategies and even if it could mean support the athlete to avoid his/her negative superstitious beliefs.

In sport, there is emerging evidence to suggest that some athletes are engaging superstitious practices such as lucky charms to facilitate performance enhancement (Damisch et al., 2010; Ofori, Tod, \& Lavallee, in press). The effectiveness of such practices is currently unclear, but research is needed to compare the effects of types of superstitions, against more traditional approaches to dealing with stress and anxiety in sport, using both superstitious and nonsuperstitious participants (to control for belief). Researchers should also be prepared to compare and contrast physiological, biochemical, affective and neurological data in order to explore possible mechanisms to explain any observed changes in different types of sports. There is also the need for further research in the area of religious faith based coping strategies of elite athletes 


\section{Predictors of Superstitious Beliefs}

and how cultural based practices inform athletes control and coping strategies. Future research is warranted to explore the potential of a collaborative partnership between the sport psychologist and team's religious leaders (chaplain/ Imam/fetish priest) and how they could work more effectively with significant others (i.e., coaches and administrators) to provide support to their athletes.

In addition, the last decade or two, there has been an interest in issues of cultural diversity in sport and calls for culturally informed sport psychology research and practice (e.g., Hanrahan, 2011; Ryba, Stambulova, Si, \& Schinke, 2013; Schinke \& Moore, 2011; Stambulova \& Ryba, 2014). There is need to broaden practice in the sport psychology with special interest in clients religious, traditional and cultural practices. This approach challenges culture-blind theories, research, and practice, and moves the sport psychology field from decontextualized knowledge to a new way of thinking about athletes as constituted by various discourses and identities (Ryba et al., 2013).

From an applied perspective, the present findings advocate the need for more client-centred approaches in sport psychology consultations. It is important to draw attention to some of the implications of including superstitious dimensions in this process - especially if they are based on religious belief or cultural practices. Simons (1992) was quick to differentiate rational mental plans and routines from superstitious rituals. His position, like the majority of sports

psychologists (Kirschenbaum, 1984; Orlick, 2000; Weinberg \& Gould, 2003), is that interventions should be based on maximising an athletes' control over his or her mental state, and by so doing promote self-regulation and more control over performance. There is an abundance of controlled scientific support for the use of mental skills training as a means of 


\section{Predictors of Superstitious Beliefs}

improving performance (Greenspan \& Feltz, 1989; Weinberg \& Comar, 1994) but if due to the athletes worldview, superstition is the only way to gain control, reduce stress and cope with uncertainties, respect the athlete situation and support him/her to make good use of it. while sports psychologists need to acknowledge individuals superstitious beliefs, it is important that the main goals of the consultation are not lost (Crust, 2006). It is important to help athletes cope effectively by developing control and coping strategies is paramount and if this can be achieve through the athletes use of superstition then so be it. Although, there is far more evidence to suggest performance improvements, coping effectiveness and feeling of control are best achieved by using the more traditional mental skills that a sport psychologist has at his or her disposal, than by use of superstition.

\section{Limitations of the study}

A major limitation of the present study was the limited psychometric properties of the scale used in measuring superstitious beliefs. Also, the Cronbach's Alpha Coefficients for General external control and Exagginternal control were low and this might have attenuated observed relationships. Another limitation of the study was the attempt to measure superstitious beliefs with survey, whereas this understanding would be much strengthened by the use of qualitative research. Future studies should adopt mixed-method approach investigate the differences between the types of superstitious beliefs and behavior among team and individual sport athletes on functional dysfunctional purpose of superstition in sport. Also how functional superstitions can be incorporate in the sport science support intervention programme.

\section{Conclusion}




\section{Predictors of Superstitious Beliefs}

In conclusion, the results suggest that athletes may activate different types of superstitious beliefs to cope or gain control. Athlete's superstitious beliefs may act as palliative coping strategy and as a secondary control strategy to create feelings of control during situations of uncertainty. In relation to applied practice, sport psychologists need to respect athletes' beliefs, practices, and values emanating from culture and are associated with religion and superstition. Evidence herein suggests that superstition is functional to its believers. The extent of the functionality superstitious beliefs to believers could be determinant of the type of superstition (positive or negative) and psycho-social orientation. This evidence provides important information for coaches and sport psychologists to take into consideration when designing interventions.

\section{Reference}

Alloy, L.B., Abramson, L. Y. (1982). "Learned Helplessness, Depression, and the Illusion of Control." J. Pets. Soc. Psychol. 42: 1114-26.

Archetti, E. P. (1999). Masculinities: Football, polo and the tango in Argentina. Oxford: Berg. 


\section{Predictors of Superstitious Beliefs}

Becker, J. (1975). Superstition in sport. International Journal of Sport Psychology, 6, 148152.

Berrenberg, J. L. (1987). The Belief in Personal Control Scale: A measure of Godmediated and exaggerated control. Journal of Personality Assessment,51, 194-206. doi:10.1207/s15327752jpa5102_4

Bersabe, R \& Martınez Arias, R. (2000). Superstition in Gambling. Psychology in Spain, 4, 28-34.

Birrell S. (1981). Sport as ritual: interpretations from Durkheim to Goffman. Soc Forces: 60: 354-376. DOI: $10.2307 / 2578440$

Bleak, J. L. \& Frederick, C. M. (1998). Superstitious behavior in sport: Levels of effectiveness and determinants of use in three collegiate sports. Journal of Sport Behavior, 21, 1-15.

Broch, T.B, \& Kristiansen, E. (2014). “The margin for error”: Ritual coping with cultural pressures. Scandinavian Journal of Medicine \& Science in Sports, 24, 837-845. doi: 10.1111/sms.12077

Buhrmann, H. G. \& Zaugg, M. K. (1981). Superstitions among basketball players: An investigation of various forms of superstitious beliefs and behavior among competitive basketballers at the junior high school to university level. Journal of Sport Behavior,4,163-174.

Buhrmann, H. G. \& Zaugg, M. K. (1983). Religion and superstition in the sport of basketball. Journal of Sport Behavior, 6, 146-157.

Burger, J. M, \& Lynn, A. L. (2005). Superstitious behavior among American and Japanese professional baseball players. Basic and Applied Social Psychology, 27, 71-76. doi:10.1207/s15324834basp2701_7 


\section{Predictors of Superstitious Beliefs}

Burke, K. L., Czech, D. R., Knight, J. L., Scott, L. A., Joyner, A. B., Benton, S. G., \& Roughton, H. K. (2006). An exploratory investigation of superstition, personal control, optimism and pessimism in NCAA Division I intercollegiate studentathletes. Athletic Insight: The Online Journal of Sport Psychology, 8 (2). Retrieved from :http://www.athleticinsight.com/Vol8Iss2/Superstition.htm

Carlson, B. D., Mowen, J. C., \& Fang, X. (2009). Trait superstition and consumer behavior: Reconceptualization, measurement, and initial investigations. Psychology \& Marketing, 26(8), 689-713. DOI: 10.1002/mar.20295

Carver, C. S. (1997). "You want to measure coping but your protocol's too long: Consider the Brief COPE.” International Journal of Behavioral Medicine, 4, 92-100.

Case, T. I., Fitness, J., Cairns, D. R., \& Stevenson, R. J. (2004). Coping with uncertainty: Superstitious strategies and secondary control. Journal of Applied Social Psychology, 34, 848-871. doi: 10.1111/j.1559-1816.2004.tb02574.x

Coakley, J. J. (1998). Sport in society: Issues and controversies (6 $6^{\text {th }}$ ed.). London: Mosby Publishers.

Cohn, P. J. (1990). Preperformance routines in sport: Theoretical support and practical applications. The Sport Psychologist, 4, 301-312.

Cottingham, M. D. (2012) Interaction ritual theory and sport fans: emotion, symbols, and solidarity. Sociol Sport J, 29: 168-185.

Cook, C. M., \& Persinger, M. A. (1997). Experimental induction of the "sensed presence" in normal subjects and an exceptional subject. Perceptual and Motor Skills, 85, 683. doi: 10.2466/pms.1997.85.2.683 


\section{Predictors of Superstitious Beliefs}

Crust, L. (2006). Challenging the 'Myth' of a Spiritual Dimension in Sport. Athletic Insight: The Online Journal of Sport Psychology, 8 (2). Retrieved from: http://www.athleticinsight.com/Vol8Iss2/Superstition.htm

Czech, D. R., Wrisberg, C., Fisher, L., Thompson, C., \& Hayes, G. (2004). The experience of Christian prayer in sport - An existential phenomenological investigation. Journal of Psychology and Christianity, 2, 1-19.

Damisch L, Stoberock B, \& Mussweiler T. (2010). Keep Your Fingers Crossed! How Superstition Improves Performance. Psychological Science, 21(7) 1014- 1020. doi:10.1177/0956797610372631

Dudley, R.T. (1999). "The Effect of Superstitious Belief on Performance Following an Unsolvable Problem." Personality and Individual Differences, 26(6): 1057-1064. doi:10.1016/S0191-8869(98)00209-8

Felson, R.B. \& Gmelch, G. (1979). "Uncertainty and the Use of Magic." Current Anthropology, 20: 587-589. Retrieved from: http://www.jstor.org/stable/2742120?seq=1\#page_scan_tab_contents

Field, A. (2013). Discovering Statistics Using SPSS (3rd $\left.{ }^{\mathrm{ed}}\right)$. Thousand Oaks, CA: Sage.

Fisher S., (1986). Stress and Strategy. Lawrence Erlbaum Associates London and Hillsdale, N.J. 


\section{Predictors of Superstitious Beliefs}

Fitzsimmons, P. A., Landers, D. M., Thomas, J. R., \& Van der Mars, H. (1991). Does selfefficacy predict performance in experienced weightlifters? Research Quarterly for Exercise and Sport, 62, 424-431. DOI:10.1080/02701367.1991.10607544

Haselton, M.G. and Nettle, D. (2006). "The Paranoid Optimist: An Integrative Evolutionary Model of Cognitive Biases." Personality and Social Psychology Review 10(1): 47-66. doi: 10.1207/s15327957pspr1001_3

Heckhausen, J., Wrosch, C., \& Fleeson, W. (2001). Developmental regulation before and after a developmental deadline: The sample case of "biological clock" for child-bearing. Psychology and Aging, 16, 400-413. doi.org/10.1037/0882-7974.16.3.400

Gmelch, G. (2004). Baseball magic. In: Ferraro G, ed. Classic readings in cultural Anthropology. Toronto: Thomson.

Greening, L., \& Stoppelbein, L. (2007). Brief report: pediatric cancer, parental coping style, and risk for depressive, posttraumatic stress, and anxiety symptoms. Journal of Pediatric Psychology, 32(10), 1272-1277. doi: 10.1093/jpepsy/jsm057

Groth-Marnat, G., \& Pegden, J. (1998). Personality correlates of paranormal belief: Locus of control and sensation seeking. Social Behavior and Personality, 26(3), 291-296. DOI: http://dx.doi.org/10.2224/sbp.1998.26.3.291

Greenspan, M. J., \& Feltz, D. F. (1989). Psychological interventions with athletes in competitive situations: A review. The Sport Psychologist, 3, 219-236. 


\section{Predictors of Superstitious Beliefs}

Gross, R. D. (2001). Psychology: The science of mind and behaviour (4 ${ }^{\text {th }}$ ed). London: Hodder \& Stoughton.

Jones, G., \& Swain, A. (1995). Predispositions to experience debilitative and facilitative anxiety in elite and non-elite performers. The Sport Psychologist, 9, 201-211.

Keinan, G. (1994). " Effects of Stress and Tolerance of Ambiguity on Magical Thinking." Journal of Personality and Social Psychology, 67: 48-55. http://dx.doi.org/10.1037/00223514.67.1.48

Keinan, G. (2002). "The Effects of Stress and Desire for Control on Superstitious Behavior." Personality and Social Psychology Bulletin, 28: 102-108. doi: $10.1177 / 0146167202281009$

Kirschenbaum, D. S. (1984). Self-regulation and sport psychology: Nurturing an emerging symbiosis. Sport Psychology, 6 (2), 159-183.

Kristiansen, E., Roberts, G. C., Abrahamsen, F.E. (2008). Achievement involvement and stress coping in elite wrestling. Scandinavian Journal of Medicine \& Science in Sports, 18, 526-538. DOI: 10.1111/j.1600-0838.2007.00646.x

Lachmann, G. (2005). Wo bleiben Weisheit und Weihrauch?: Jeder Zweite ist abergläubisch. URL: http://www.presseportal.de/meldung/760788/.Retrieved 03/15/2008.

Lachman, M.E \& Weaver, S.L (1998a). Sociodemographic variations in the sense of control by domain: Findings from the MacArthur studies of midlife. Psychology and Aging, 13(4), 553-62. http://dx.doi.org/10.1037/0882-7974.13.4.553 


\section{Predictors of Superstitious Beliefs}

Lawrence, I. (2005). The emergence of 'sport and spirituality' in popular culture. The Sport Journal, 8 (2). Retrieved June 29, 2005, from http://www.thesportjournal.org /2005 Journal/vol8-No2/ian-lawrence.asp

Lazarus, R. S., \& Folkman, S. (1984). Stress, appraisal, and coping. New York: Springer.

Morling, B., \& Evered, S. (2006). Secondary control reviewed and defined. Psychological Bulletin, 132, 269-296. http://dx.doi.org/10.1037/0033-2909.132.2.269

Mowen, J. C., \& Carlson, B. (2003). Exploring the antecedents and consumer behavior consequences of the trait of superstition. Psychology \& Marketing, 20(12), 1045-1065. DOI: $10.1002 / \mathrm{mar} .10108$

Neil, G. I. (1982). Demystifying sport superstition. International Review of Sport Sociology, 17, 99-124. doi: 10.1177/101269028201700108

Nelson, L. R., \& Furst, M. L. (1972). An objective study of the effects of expectation on competitive performance. Journal of Psychology, 81, 69-72. DOI:

$10.1080 / 00223980.1972 .9923790$

Ness, R. G., \& Patton, R. W. (1979). The effect of beliefs on maximum weightlifting performance. Cognitive Therapy and Research, 3, 205-211.

Nesti, M. (2004). Existential psychology and sport: Implications for research and practice. London: Routledge.

Ofori, P.K., Tod, D., \& Lavallee, D. (in press). An Exploratory Investigation of Superstitious Behaviors, Coping, Control Strategies, and Personal Control in Ghanaian and British Student-Athletes. International Journal of Sport and Exercise Psychology. 


\section{Predictors of Superstitious Beliefs}

Ofori, P.K. (2013). Psychological Consequences of Superstition in Sports. Unpublished PhD thesis, University of Stirling, UK.

Ofori, P. K., Biddle S., and Lavallee, D. (2012).The role of superstition among professional footballers in Ghana. Athletic Insight, 4(2), 115-126.Availableat: http://www.athleticinsight.com/Vol14Iss2/Feature.htm

Orlick, T. (2000). In pursuit of excellence ( $3^{\text {rd }}$ ed.). Champaign, IL: Human Kinetics.

Park, J. (2000). Coping strategies by Korean national athletes. The Sport Psychologist, 14, 63-80.

Pearlin, L.I. and Schooler, C. (1978).The structure of coping. Journal of Health and Social Behavior19: 2-21. http://www.jstor.org/stable/2136319

Peng, Y., \& Lachman, M. E. (1994).Primary and secondary control: Cross-cultural and lifespan developmental perspectives. Paper presented at the 13th Biennial Meeting of Institutional Society for the Study of Behavioral Development, Amsterdam, The Netherlands.

Perczek, R., Carver, C. S., Price, A. A., \& Pozo-Kaderman C. (2000). Coping, mood, and aspects of personality in Spanish translation and evidence of convergence with English versions. Journal of Personality Assessment, 74, 63-87. DOI:10.1207/S15327752JPA740105

Peterson, C. (1978). Focus of control and belief in self-oriented superstitions. The Journal of Social Psychology, 105, 305-306. DOI: 10.1080/00224545.1978.9924131

Persinger, M. A. (1987). Neuropsychological bases of god beliefs. Westport, CT: Greenwood. 


\section{Predictors of Superstitious Beliefs}

Rothbaum, F., Weisz, J. R., \& Snyder, S. S. (1982). Changing the world and changing the self: A two-process model of perceived control. Journal of Personality and Social psychology, 42, 5-37. http://dx.doi.org/10.1037/0022-3514.42.1.5

Rotter, J. B. (1966). Generalized expectancies for internal versus external control for Reinforcement. Psychological Monographs, 80 (1, Whole No. 609). http://dx.doi.org/10.1037/h0092976

Schinke, R., \& Moore, Z. E. (2011). Culturally informed sport psychology: Introduction to the special issue. Journal of Clinical Sport Psychology, 5(4), 283.

Schippers, M.C. and Van Lange, P.A.M. (2006). "The Psychological Benefits of Superstitious Rituals in Top Sport: A Study among Top Sportspersons." Journal of Applied Social Psychology, 36(10): 2532-2553. DOI: 10.1111/j.0021-9029.2006.00116.x

Simons, J. (1992). Optimizing performance through mental plans and physical routines. Track and Field Quarterly, 92(1), 17-21.

Thompson, S.C. (1981). " Will It Hurt Less If I Can Control It? A Complex Answer to a Simple Question " Psychological Bulletin,90: 89-101. http://dx.doi.org/10.1037/00332909.90.1.89

Tobacyk, J., Mark, J., Miller, P. M., \&Thomas M. (1988). “Comparisons of Paranormal Beliefs of Black and White University Students from the Southern United States.” Psychological Reports 63(2):492-94. doi: 10.2466/pr0.1988.63.2.492

Tobacyk, J. (1988). A revised paranormal belief scale. Unpublished manuscript, Louisiana Tech University, Rushton, LA. 


\section{Predictors of Superstitious Beliefs}

Tobacyk, J. (2004). A revised paranormal belief scale. The International Journal of Transpersonal Studies, 23, 94-99.

Tobacyk, J. [J.], \& Milford, G. (1983). Belief in paranormal phenomena: Assessment instrument development and implications for personality functioning. Journal of Personality and Social Psychology,44, 1029-1037. http://dx.doi.org/10.1037/0022-3514.44.5.1029

Tobacyk, J. J., Nagot, E., \& Miller, M. (1988). Paranormal beliefs and locus of control: A multidimensional examination. Journal of Personality Assessment, 52, 241-246. DOI: 10.1207/s15327752jpa5202_5

Todd, M., \& Brown, C. (2003). Characteristics associated with superstitious behavior in track and field athletes: Are there NCAA divisional level differences? Journal of Sport Behavior, 26, 168-187.

Van Raalte, J L, Brewer, B. W., Nemeroff, C. J., \& Linder, D. E. (1991). Chance orientation and superstitious behavior on the putting green. Journal of Sport Behavior, 14, $41-50$.

Wager, T.D., Rilling, J.K., Smith, E.E., et al. (2004). "Placebo-Induced Changes in Fmri in the Anticipation and Experience of Pain." Science,303(5661): 1162-1167. DOI: $10.1126 /$ science. 1093065

Wargo, E. (2008). The many lives of superstition. APS Observer, 21, 18-24. 


\section{Predictors of Superstitious Beliefs}

Watson, J. and Nesti, M. (2005). The Role of Spirituality in Sport Psychology Consulting: An Analysis and Integrative Review of Literature. Journal of Applied Sport Psychology, 17(3), 228-239. DOI:10.1080/10413200591010102

Weinberg, R. S., \& Comar, W. (1994). The effectiveness of psychological interventions in competitive sport. Sports Medicine, 18, 406-418. DOI

10.2165/00007256-199418060-00005

Weinberg, R. S., \& Gould, D. (2003). Foundations of sport and exercise psychology ( $3^{\text {rd }}$ ed.). Champaign, IL: Human Kinetics.

Whitson, J. A., \& Galinsky, A. D. (2008). Lacking control increases illusory pattern perception. Science, 322(5898), 115-117.DOI: 10.1126/science.1159845

Wiseman, R. (2003). The Luck Factor: The scientific study of the lucky mind. London: Random House.

Wright, P. B., \& Erdal, K. J. (2008). Sport superstition as a function of skill level and task difficulty. Journal of Sport Behavior, 31(2), 187.

Wrosch, C., \& Heckhausen, J. (1999). Control processes before and after passing a developmental deadline: Activation and deactivation of intimate relationship goals. Journal of Personality and Social Psychology, 77, 415-427. http://dx.doi.org/10.1037/0022-3514.77.2.415 


\section{Predictors of Superstitious Beliefs}

Wrosch, C., Heckhausen, J., \& Lachman, M. E. (2000). Primary and secondary control strategies for managing health and financial stress across adulthood. Psychology and Aging, 15, 387-399. http://dx.doi.org/10.1037/0022-3514.77.2.415

Table 1

Gender and Age Statistics

\begin{tabular}{lccc}
\hline Gender & Mean Age & Age Range & $\mathrm{N}$ \\
\hline Females & 24.5 & $19-30$ & 165 \\
Males & 26 & $19-33$ & 210 \\
\hline
\end{tabular}


Predictors of Superstitious Beliefs

Table 2: Summary of means and standard deviation for variables

\begin{tabular}{lllll}
\hline & $\mathrm{N}$ & Mean & $\begin{array}{l}\text { Standard } \\
\text { Deviation }\end{array}$ & $\begin{array}{l}\text { Cronbach's } \\
\text { Alpha }\end{array}$ \\
\hline Self-distraction (COPE) & 361 & 5.41 & 1.31 & .62 \\
Active coping (COPE) & 363 & 5.81 & 1.18 & .62 \\
Denial (COPE) & 363 & 3.69 & 1.34 & .62 \\
Substance use (COPE) & 363 & 2.8 & 1.3 & .67 \\
Emotional support (COPE) & 361 & 4.84 & 1.39 & .60 \\
Instrumental support (COPE) & 361 & 5.23 & 1.44 & .60 \\
Behavioural disengagement (COPE) & 361 & 3.29 & 1.2 & .65
\end{tabular}




\section{Predictors of Superstitious Beliefs}

$\begin{array}{lllll}\text { Venting (COPE) } & 361 & 4.76 & 1.25 & .62 \\ \text { Positive reframing (COPE) } & 360 & 4.76 & 1.25 & .60 \\ \text { Planning (COPE) } & 361 & 5.69 & 1.26 & .61 \\ \text { Humor (COPE) } & 361 & 4.87 & 1.62 & .64 \\ \text { Acceptance (COPE) } & 361 & 5.28 & 1.21 & .61 \\ \text { Religion (COPE) } & 361 & 4.49 & 2.3 & .66 \\ \text { Self-blame (COPE) } & 361 & 4.82 & 1.54 & .63 \\ \text { General external control (BPCS) } & 356 & 41.98 & 7.48 & .23 \\ \text { Exagginternal control (BPCS) } & 356 & 66.08 & 9.6 & .23 \\ \text { God mediated control (BPCS) } & 356 & 26.8 & 14.16 & -.04 \\ & & & & .83 \\ \text { Negative superstitious Beliefs (BSQ) } & 370 & 6.71 & 2.99 & .83 \\ \text { Positive superstitious Beliefs (BSQ) } & 370 & 7.61 & 2.93 & \\ \text { Age } & 375 & 22.71 & 4.38 & \\ \text { Valid N (listwise) } & 349 & & & \end{array}$

Table 3

Summary of correlations between measures of belief in personal control, coping, control strategies and superstitious behaviour

\begin{tabular}{lll}
\hline Independent Variables & $\begin{array}{l}\text { Negative } \\
\text { Superstitious } \\
\text { Beliefs }\end{array}$ & $\begin{array}{l}\text { Positive } \\
\text { Superstitious } \\
\text { Beliefs }\end{array}$ \\
\hline Self-distraction & .05 & $.13^{*}$ \\
Active coping & -.08 & $-.12^{*}$ \\
Denial & -.01 & -.04 \\
Substance use & $.30^{* *}$ & $.35^{* *}$ \\
Emotional support & $.20^{* *}$ & $.22^{* *}$ \\
Instrumental support & .07 & .07 \\
Behavioural disengagement & $.12^{*}$ & .04
\end{tabular}




\section{Predictors of Superstitious Beliefs}

$\begin{array}{lll}\text { Venting } & -.06 & -.06 \\ \text { Positive reframing } & -.11^{*} & -.09 \\ \text { Planning } & -.16^{* *} & -.15^{* *} \\ \text { Humour } & .08 & .17^{* *} \\ \text { Acceptance } & -.10 & -.16^{* *} \\ \text { Religion } & -.35^{* *} & -.41^{* *} \\ \text { Self-blame } & .21^{* *} & .28^{* *} \\ \text { General external control } & .17^{* *} & .17^{* *} \\ \text { God-mediated control } & .34^{* *} & .43^{* *} \\ \text { Exaggerated internal control } & -.19^{* *} & -.13^{*} \\ & & \\ \text { Primary Control } & -.06 & -.06 \\ \text { SSC } & -.15^{* *} & -.23^{* *} \\ \text { CSC } & .21^{* *} & .20^{* *}\end{array}$

** Correlation is significant at .01 level

*Correlation is significant at .05 level

Table 4

Sequential regression analyses predicting negative superstitious beliefs from secondary control, coping mechanisms and personal control measures

\begin{tabular}{|c|c|c|c|c|}
\hline Predictor & B & SE B & $\boldsymbol{\beta}$ & $\Delta \mathbf{R}^{2}$ \\
\hline Step 1 & & & & $.18 * * *$ \\
\hline Constant & 10.55 & .92 & & \\
\hline Age & .04 & .04 & .05 & \\
\hline Gender & -1.40 & .30 & $-.23 * * *$ & \\
\hline Ethnicity & -.31 & .05 & $-.36 * * *$ & \\
\hline
\end{tabular}

$\begin{array}{llll}\text { Step 2 } & & & \\ \text { Constant } & 9.53 & 1.22 & .04 \\ \text { Age } & .03 & .04 & -.23^{* * * *} \\ \text { Gender } & -1.39 & .29 & -34 * * * \\ \text { Ethnicity } & -.30 & .05 & \\ & & & -.08 \\ \text { SSC } & -.10 & .07 & .18^{* * *} \\ \text { CSC } & .22 & .06 & \end{array}$




\section{Predictors of Superstitious Beliefs}

\begin{tabular}{|c|c|c|c|c|}
\hline Step 3 & & & & $.06 * * *$ \\
\hline Constant & 11.68 & 1.94 & & \\
\hline Age & .03 & .03 & .04 & \\
\hline Gender & -1.42 & .29 & $-.24 * * *$ & \\
\hline Ethnicity & -.22 & .06 & $-.25 * * *$ & \\
\hline SSC & -.04 & .07 & -.03 & \\
\hline CSC & .14 & .06 & $.12^{*}$ & \\
\hline $\begin{array}{l}\text { General external } \\
\text { control }\end{array}$ & .02 & .02 & .04 & \\
\hline $\begin{array}{l}\text { God-mediated } \\
\text { control }\end{array}$ & .04 & .02 & $.18^{*}$ & \\
\hline $\begin{array}{l}\text { Exaggerated } \\
\text { internal control }\end{array}$ & -.07 & .02 & $-.22 * * *$ & \\
\hline Step 4 & & & & $.04 *$ \\
\hline Constant & 9.28 & 2.26 & & \\
\hline Age & .04 & .03 & .06 & \\
\hline Gender & -1.35 & .28 & $-.22 * * *$ & \\
\hline Ethnicity & -.21 & .06 & $-.24 * *$ & \\
\hline SSC & -.01 & .08 & -.01 & \\
\hline CSC & .08 & .06 & .06 & \\
\hline $\begin{array}{l}\text { General } \\
\text { external control }\end{array}$ & .01 & .02 & .01 & \\
\hline $\begin{array}{l}\text { God-mediated } \\
\text { control }\end{array}$ & .03 & .02 & $.16^{*}$ & \\
\hline $\begin{array}{l}\text { Exaggerated } \\
\text { internal control }\end{array}$ & -.05 & .02 & $-.17 * *$ & \\
\hline Substance use & .27 & .12 & $.12 *$ & \\
\hline $\begin{array}{l}\text { Emotional } \\
\text { support }\end{array}$ & .27 & .11 & $.13^{*}$ & \\
\hline $\begin{array}{l}\text { Behavioural } \\
\text { disengagement }\end{array}$ & .17 & .13 & .07 & \\
\hline $\begin{array}{l}\text { Positive } \\
\text { reframing }\end{array}$ & -.14 & .13 & -.06 & \\
\hline Planning & -.05 & .13 & -.02 & \\
\hline Self- blame & .05 & .10 & .03 & \\
\hline
\end{tabular}

Note: $* p<.05 \quad * * p<.01 * * * p<.001$ 
Predictors of Superstitious Beliefs

Table 5

Sequential regression analyses predicting positive superstitious beliefs from secondary control, coping mechanisms and personal control measures

\begin{tabular}{llll} 
Predictor & B & SE B & $\boldsymbol{\beta}$ \\
\hline Step 1 & & & \\
Constant & 12.76 & .85 & .00 \\
Age & .00 & .03 & .00 \\
Gender & -1.64 & .28 & $-.28 * * *$ \\
Ethnicity & -.37 & .04 & $-.44 * * *$
\end{tabular}

Step 2

Constant

Age

Gender

Ethnicity

SSC
12.59

0

$-1.6$

$-.36$

$-.18$
1.12

.03

.27

.04

.06

$\Delta \mathbf{R}^{2}$

$.27 * * *$


Predictors of Superstitious Beliefs

\begin{tabular}{|c|c|c|c|c|}
\hline CSC & .20 & .05 & $.17 * * *$ & \\
\hline Step 3 & & & & $.04 * * *$ \\
\hline Constant & 14.23 & 1.78 & & \\
\hline Age & 8.2 & .03 & .00 & \\
\hline Gender & -1.65 & .26 & $-.28 * * *$ & \\
\hline Ethnicity & -.25 & .06 & $-.29 * * *$ & \\
\hline SSC & -.15 & .07 & $-.11^{*}$ & \\
\hline CSC & .15 & .06 & $.13^{*}$ & \\
\hline $\begin{array}{l}\text { General } \\
\text { external } \\
\text { control }\end{array}$ & .0 & .02 & -.01 & \\
\hline $\begin{array}{l}\text { God- } \\
\text { mediated } \\
\text { control }\end{array}$ & .05 & .01 & $.23^{* *}$ & \\
\hline $\begin{array}{l}\text { Exaggerated } \\
\text { internal } \\
\text { control }\end{array}$ & -.05 & .01 & $-.17 * * *$ & \\
\hline Step 4 & & & & $.07 * * *$ \\
\hline Constant & 10.23 & 2.06 & & \\
\hline Age & .02 & .03 & .03 & \\
\hline Gender & -1.48 & .26 & $-.25 * * *$ & \\
\hline Ethnicity & -.21 & .05 & $-.25 * * *$ & \\
\hline SSC & -.14 & .07 & $-.11^{*}$ & \\
\hline CSC & -.07 & .06 & .06 & \\
\hline $\begin{array}{l}\text { General } \\
\text { external } \\
\text { control }\end{array}$ & .01 & .02 & .02 & \\
\hline $\begin{array}{l}\text { God- } \\
\text { mediated } \\
\text { control }\end{array}$ & .04 & .01 & $.18^{*}$ & \\
\hline $\begin{array}{l}\text { Exaggerated } \\
\text { internal } \\
\text { control }\end{array}$ & -.04 & .01 & $-.13^{*}$ & \\
\hline $\begin{array}{l}\text { Self- } \\
\text { distraction }\end{array}$ & .12 & .10 & .05 & \\
\hline $\begin{array}{l}\text { Active } \\
\text { coping }\end{array}$ & .20 & .13 & .08 & \\
\hline $\begin{array}{l}\text { Substance } \\
\text { use }\end{array}$ & .33 & .10 & $.15^{* *}$ & \\
\hline $\begin{array}{l}\text { Emotional } \\
\text { support }\end{array}$ & .29 & .10 & $.14 * *$ & \\
\hline Planning & -.05 & .13 & -.02 & \\
\hline
\end{tabular}


Predictors of Superstitious Beliefs

$\begin{array}{llll}\text { Humour } & .03 & .09 & .02 \\ \text { Acceptance } & -.34 & .11 & -.14 * * \\ \text { Self- blame } & .17 & .09 & .09 \\ & & & \\ * p<.05 \quad * * p<.01 * * * p<.001 & \end{array}$

